\title{
Investigation of stress field parameters at deep horizons of the Gayskoye field**
}

\author{
Sergey Sentyabov ${ }^{1 *}$ and Albert Zubkov ${ }^{1}$ \\ ${ }^{1}$ Federal State Budgetary Institution of Science, Institute of Mining of the Ural Branch of Russian \\ Academy of Sciences, Ekaterinburg, Russia
}

\begin{abstract}
The extraction of solid minerals is associated with the penetration of man into the subsoil by creating either relatively simple or extremely complex structures. All mining operations can be safely and efficiently carried out only on the basis of calculating the stability of these structures, which is based on knowledge of the physical and mechanical properties, the stress state of the rock mass and the patterns of their redistribution and formation in mountain structures. The presented studies confirmed the regularities of the formation of natural stresses in the rock mass, which is the sum of gravitational, static tectonic and variable components, which are formed as a result of uniform periodic volumetric expansion and contraction of the Earth. The problem of shaft stability is due to the need to solve problems to determine the level of stress-strain state and strength properties in concrete lining. The parameters of stresses in the shaft lining and monitoring of their changes were determined using the method of measuring unloading deformations. When analyzing the stresses obtained experimentally by analytical means in the concrete lining of mine shafts, a connection was established with the results of measurements in the rock mass on the basis of 50 meters. Based on the experiment, it was confirmed that theoretical and experimental studies prove that a hierarchically blocky massif of magmatic and metamorphic rocks behaves as an elastic and isotropic medium and changes in natural stresses in the massif $\Delta$ on the basis of 5-7 ranks of geoblocks, on the contour of the trunk based on 2-3 ranks of geoblocks and in the concrete lining of mine shafts $\Delta \sigma b$ obey this law. Key words: concrete lining of shafts; stress-strain state; drooping; sustainability; crevice unloading; unloading deformation; physical and mechanical properties.
\end{abstract}

\section{Introduction}

At present, a large-scale reconstruction of the shafts of the underground mine of PJSC Gaysky GOK has been carried out. In order to increase the productivity of the Gayskoye underground mine, a strategic project for the development of the plant "Opening and development of deep horizons at the $-830 \ldots-1310$ meters underground mine floor" was

\footnotetext{
*Corresponding authors: sentyabov1989@mail.ru

${ }^{* *}$ The research was carried out within the framework of the state assignment No. 07500581-19-00 on the topic No. 0405-2019-0007
} 
developed. This project addresses the issues of opening and development of deep horizons of an underground mine, development of new ore delivery schemes, reconstruction of mine shafts and their deepening up to -1420 meters from the surface [2-3].

Since 2013, the Gayskoye underground mine has been monitoring the stress-strain state of the shaft lining. In 2020, studies of changes in stresses in the lining of the Kletovaya shaft and the rock mass at different horizons continued.

At this stage of research, the changes in stresses acting in the lining of the Kletovaya shaft were determined at the field. The measurements were taken at bases of different lengths and different horizons.

The stations are installed in the running compartment of the Kletovaya mine shaft at elevations of $-830 \mathrm{~m},-910 \mathrm{~m},-990 \mathrm{~m},-1070 \mathrm{~m}$ and $-1390 \mathrm{~m}$.

Studies of the geomechanical state of the rock mass

Geomechanical field studies in the operating shaft of the Kletovaya mine at the Gaysky underground mine, conducted since 2013, are aimed at establishing the patterns of influence of time-variable stresses on the stress-strain state of the concrete lining and rock mass in the anchored space. For this purpose, every three months, measurements of the change in stresses in the concrete lining were carried out for their subsequent forecast until 2024.

The structure of the Ural geosynclinal system determined the complex nature of the stress state of the intact rock mass of the Ural deposits. The most objective characteristic of the stress state of the rock mass is the information obtained in natural conditions on the parameters of the stress tensor in the intact rock mass, due to the peculiarities of the geological conditions during the formation of deposits.

In the process of research at the Gayskoye field, field determination of the stresses of the rock mass was carried out by the slotted unloading method [1], which has proven itself well for determining the stress state in the monolithic concrete lining of shafts in the conditions of the mines of the Gaysky GOK [11].

\section{Methods for measuring and calculating the pulsating component of tectonic stresses}

The essence of the method is to measure the deformation with a dial indicator between the benchmarks before and after unloading. During the research, the slotted unloading method was significantly modernized due to the use of the latest generation gas cutters as cutting tools.

It was decided to use a saw with a diamond disc (circle) as a cutting tool. This equipment is completely autonomous, does not require connection to compressed air mains, connection to electrical networks and water supply, which allows to significantly increase the number of experimental measurements for obtaining field data, because the time for taking measurements does not exceed 20 minutes, and also expands the possibilities of choosing places for conducting research. Anchors have also undergone changes, instead of removable collet, it became possible to use permanent pewter. This made it possible to reduce the cost of their production, as well as it became possible to measure changes in the stress state in time [5-10].

As a result of the calculations, it was possible to establish the patterns of the formation of the stress-strain state of the rock mass around the unloading slot (Figure 1), as well as to establish the patterns between the stresses acting in the rock mass and displacements on the excavation contour with distance from the slot. Based on the obtained concentration coefficients, the method for calculating the initial stresses acting in the rock mass was corrected when using a disc with a diameter of $350 \mathrm{~mm}$ as a cutting tool. 


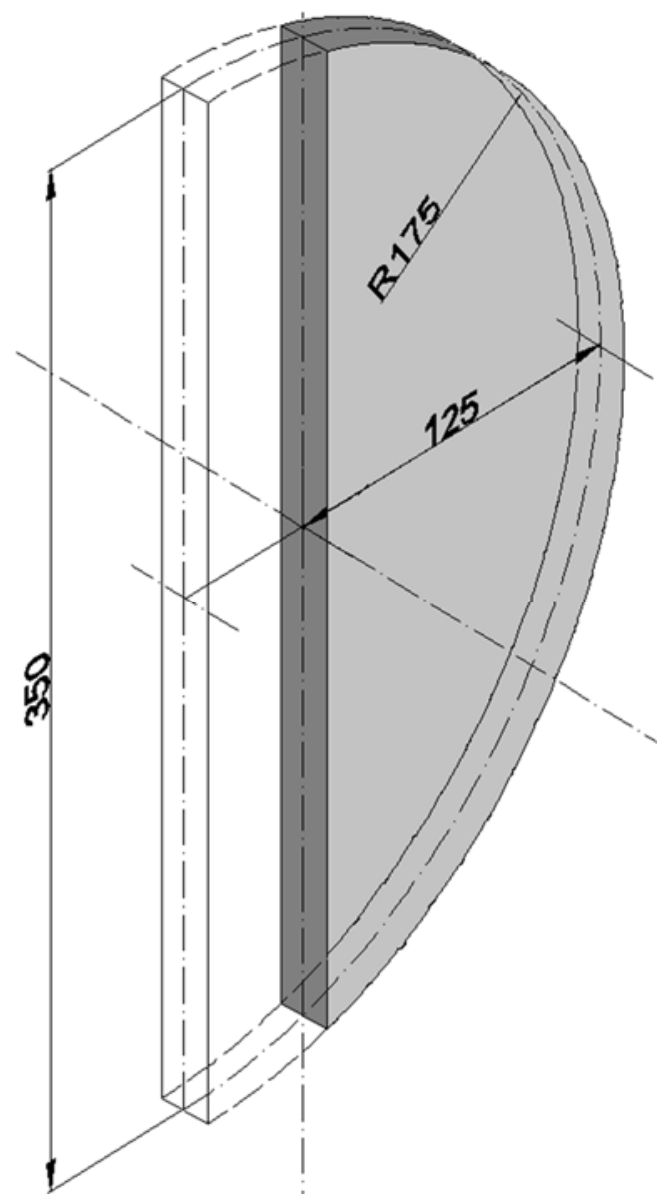

Fig. 1. Scheme for voltage measurement by the method of slot unloading.

Assessment of the gravitational-tectonic and time-variable component of the natural stress field of the rock mass at the Gayskoye field.

The conditions for determining natural stresses at the Gaysky underground mine were considered, where they were measured by the method of slotted unloading at horizons of $830 \mathrm{~m},-910 \mathrm{~m},-1075 \mathrm{~m},-1390 \mathrm{~m}$. The time-variable stresses were determined at a special test site in the near-shaft yard of the $-830 \mathrm{~m}$ horizon. The instrumentally determined stress parameters are presented in Table 1.

Table 1. Values of the initial stresses acting in the rock mass of the field.

\begin{tabular}{|c|c|c|c|c|c|}
\hline $\begin{array}{c}\text { Year of } \\
\text { measure } \\
\text { ments }\end{array}$ & $\begin{array}{c}\text { Depth, } \\
H, \mathrm{~m}\end{array}$ & $\begin{array}{c}\text { Submeridional, } \\
\sigma_{l}, \mathrm{MPa}\end{array}$ & $\begin{array}{c}\text { Sublatitudinal, } \\
\sigma_{2}, \mathrm{MPa}\end{array}$ & $\begin{array}{c}\text { Vertical, } \sigma_{z}, \\
\mathrm{MPa}\end{array}$ & $\begin{array}{c}\text { Time-varying } \\
\text { stresses, } \\
, \sigma_{A \Phi}\end{array}$ \\
\hline 1998 & -830 & -19 & -40 & -22 & -7 \\
\hline 2004 & -910 & -20 & -42 & -25 & -4 \\
\hline 2008 & -1075 & -32 & -49 & -33 & -9 \\
\hline 2019 & -1390 & -55 & -67 & -37 & -17 \\
\hline
\end{tabular}

In order to calculate the stresses in the array at the moment of time of interest to us, we need to know the magnitude of the initial stresses. For this, it is necessary to subtract the time variable component [12-16] of the moment in time when the measurements were made from the measurement results (Table 1), and add it at the moment of interest. 
The values of the initial gravity-tectonic stresses without taking into account the timevariable stresses are presented in Table 2.

Table 2. Values of the initial gravitational-tectonic stresses, excluding time-varying stresses

\begin{tabular}{|c|c|c|c|c|}
\hline $\begin{array}{c}\text { Year of } \\
\text { measurements }\end{array}$ & $\begin{array}{c}\text { Depth, } \\
H, \mathrm{~m}\end{array}$ & $\begin{array}{c}\text { Submeridional, } \\
\sigma_{l}, \mathrm{MPa}\end{array}$ & $\begin{array}{c}\text { Sublatitudinal, } \sigma_{2}, \\
\mathrm{MPa}\end{array}$ & $\begin{array}{c}\text { Vertical, } \sigma_{z}, \\
\mathrm{MPa}\end{array}$ \\
\hline 1998 & -830 & -12 & -33 & -22 \\
\hline 2004 & -910 & -16 & -38 & -25 \\
\hline 2008 & -1075 & -23 & -40 & -33 \\
\hline 2019 & -1390 & -38 & -52 & -37 \\
\hline
\end{tabular}

Figure 2 shows a graph of the change in these stresses with depth.

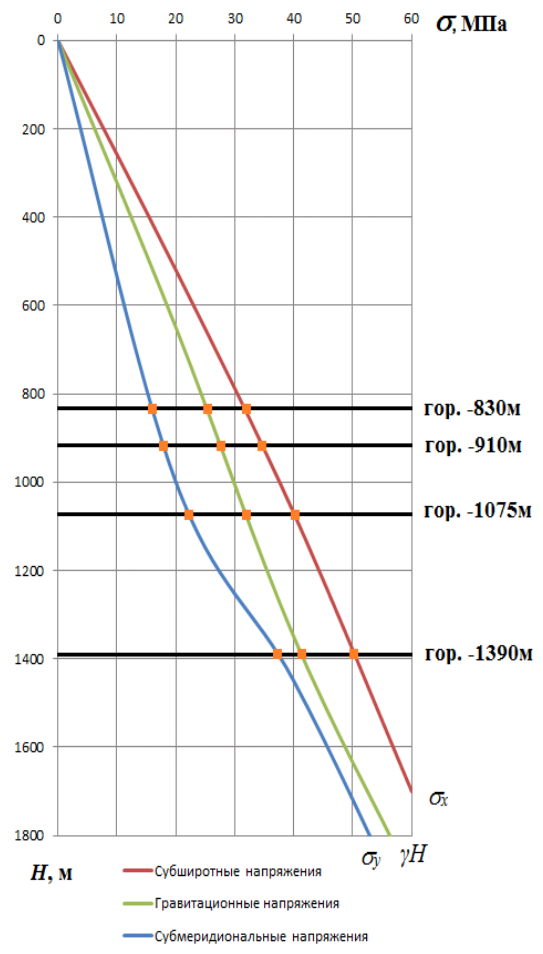

Fig. 2. Graph of changes in gravity-tectonic stresses with depth.

Taking into account the given graphs, gravity-tectonic stresses can be represented in the form of dependencies: $\sigma_{z m(x)}^{n}=\left(\sigma_{x}^{o}-0,027 H\right)=-12-0,027 H$;

$$
\sigma_{z m(y)}^{n}=\left(\sigma_{x}^{o}-0,027 H\right)=+6-0,027 H .
$$

Based on the above, we can conclude that significant gravitational-tectonic and timevariable stresses are acting in the rock mass of the "Underground mine" Gaysky GOK.

One of the factors most influencing the manifestation of rock pressure in dynamic forms is the effect of significant gravitational-tectonic stresses in the rock mass.

To conduct long-term observations of the change in the stress-strain state in the lining of the Kletovaya shaft, in 2013, observation stations were installed on the basis of 1600 $\mathrm{mm}$. The stations were installed at a depth of $-830 \mathrm{~m},-910 \mathrm{~m},-990 \mathrm{~m},-1075 \mathrm{~m}$ and -1390 $\mathrm{m}$ in the running compartment of the trunk in two positions to determine horizontal and 
vertical deformations. The change in stresses was also recorded according to the benchmarks established during slot unloading at bases $70 \mathrm{~mm}$.

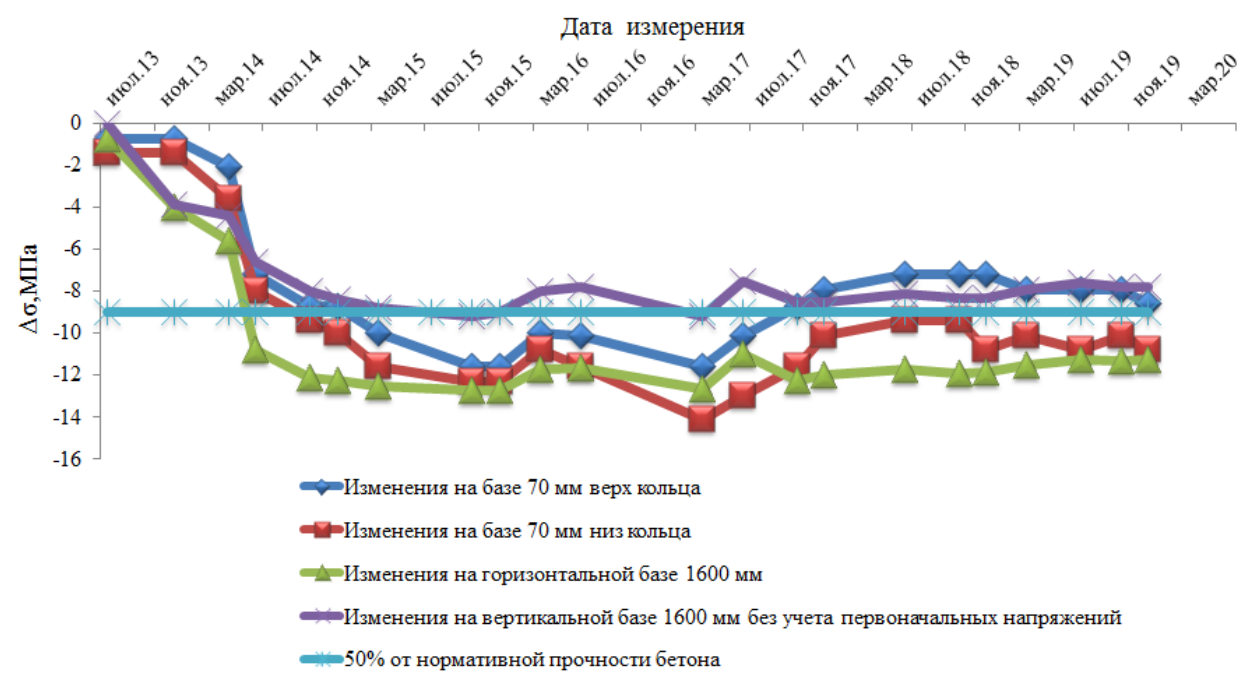

Fig. 3. Graph of stress changes in the concrete lining of the Kletovaya shaft at the horizon $-1390 \mathrm{~m}$

According to the obtained results of the design stresses in the concrete lining of the shaft of the Kletovaya mine, maximum stresses can occur, the values of the design stresses are close to the standard strength of concrete.

\section{Conclusion}

Thus, the stress state of the concrete lining of mine shafts is formed as a function of the design parameters of the shaft, the full tensor of gravitational-tectonic stresses and time variables acting in the rock mass at the time of the start of research. It is also mandatory to take into account the physical and mechanical properties of the rock mass, the modulus of concrete elasticity, which depends on the rate of withdrawal and additional stresses caused outside the zone of influence of mining by a cyclic change in natural stresses, and in the zone of influence of the mined-out space - by a change in the secondary stress field.

Based on the results of field measurements at the lower horizons of the Gaisky underground mine, the following values of natural stresses at a depth of $-1390 \mathrm{~m}$ were established: horizontal, acting across the strike of the ore body are equal to minus -67.3 $\mathrm{MPa}$, along the strike minus -55.2 MPa. Vertical stresses are on average minus $-37.0 \mathrm{MPa}$.

The established regularities of the distribution of the initial stresses of the rock mass are recommended to be used as boundary conditions for engineering calculations of the technogenic stresses of the structural elements of the operational blocks. 


\section{References}

1. A. V. Zubkov, Geomechanics and geotechnology. - Yekaterinburg: IGD UB RAS, $333 \mathrm{p}(2001)$

2. S. V. Sentyabov, Mining information and analytical bulletin, 10, 79 - 85 (2018)

3. S. V. Sentyabov, Mining information and analytical bulletin, 7, 415 - 419 (2014)

4. G.G. Yurevich, V.D. Belyakov, B.N. Sevastianov, Protection of mine workings from the effects of explosions (M, Nedra, 1972)

5. A. V. Zubkov, K.V. Selin, S.V. Sentyabov, Lithosphere, 6, 116 - 129 (2015)

6. A. V. Zubkov, Reports of the Academy of Sciences, 483(3), 1 - 11 (2018)

7. Kh.I. Abdusamatov. A deep minimum of solar radiation power will lead to a small ice age (SPb.: Nestor,. - History, 2013)

8. B.G. Tarasov, The pulsation of the earth and the cycles of geodynamic activity in the streams of space plasma (SPb: edition of MANEB, 2009)

9. V.E. Khain, M.G. Lomidze, Geotectonics with the Foundations of Geodynamics: 2nd ed. - M.; Moscow State University, 1195.- 463 p

10. E.S. Shtengelov, Bul. MOIP Dept. geol. 3, 13 - 17 (1982)

11. SV Sentyabov, Mining information and analytical bulletin (scientific and technical journal), 3-1, 211-220 (2020). DOI: 10.25018 / 0236-1493-2020-31-0-199-207

12. A. V. Zubkov, S. V. Sentyabov, Earth and environmental science: international multidisciplinary conference on industrial engineering and modern technologies "FarEastCon" (Vladivostok, Russky Island, October 1-4, 2019), 459(3), 042082 (2020). doi: 10.1088 / 1755-1315 / 459/4/042082

13. Jiang Fu-Xing, Yang Shu-Hua, Cheng Yun-Hai et al. Chinese Journal of Geophysics, 5, 1511-1516 (2006)

14. Lan Tianwei, Zhang Hongwei, Han Jun et al. Journal of Mining \& Safety enginiring, 29(6), 840-845 (2012)

15. Yu Lijiang, I. M. Batugina, A. S. Batugin, Science and Education: materials of the VI international research and practice conference, Munich, June $27^{\text {th }}-28^{\text {th }}$, 2014. Publishing office Vera VerlagWaldkraiburg-munich-Germany, 474-477 (2014) 